\title{
FAMILIAL SEX-LINKED ECTODERMAL DYSPLASIA WITH INCOMPLETE FORMS
}

\author{
BY \\ R. E. CLARKE, I.D.S., R.C.S., ENG. \\ AND \\ R. A. McCANCE, M.D., M.R.C.P.
}

(From the Dental School and the Biochemical Laboratory, King's College Hospital, London.)

Ectodermal dysplasias have both a clinical and a genetic interest. A number have been reported, but we have still much to learn about them, and since they are so rare our knowledge of them can only be furthered by accurate records of individual cases. The present case with its pedigree, therefore, is being recorded.

There is no need to review the literature, for this has been done by a number of recent writers (Janitzkaja and Rjabow ${ }^{8}$, MacKee and Andrews $^{10}{ }^{1}$ Smith $^{13}$, Parkes-Weber ${ }^{15}$, Weech ${ }^{17}$, and notably Cockayne ${ }^{2}$ ), but to assist in tracing similar cases a few of the more important references have been given.

\section{Case report.}

E. G., aged 14 years, was brought up to the dental department of King's College Hospital for advice about his teeth. Something of his appearance may be judged from his photographs (Fig. 1 and 2). In physical and mental features he is similar to other cases reported. In intelligence he is normal, if anything above normal.

Teeth and Jaws.- The boy has only had five teeth. When first seen, one was merely a decayed fragment which has now been removed. The other four are conical, strong teeth, standing in the four canine situations and occluding with one another (Fig. 1 and 3). They are not truly homologous with any normal tooth, being quite conical. The enamel ends in a strong unfestooned ring, and the root is single, strong and well developed (Fig. 3 and 4). The fragment was also single rooted.

The gums are firm and healthy and the periodontal membrane and supporting alveolus are normal radiographically.

There is no history of any other teeth and the present ones did not commence to erupt till the age of five. The alveolar bone of the jaws has no enlarged areas suggestive of erupting teeth, and, excepting round the standing teeth, measures nowhere more than one-eighth of an inch across, and has a hard smooth edge. Radiographs show no trace of other teeth, tooth germs, or empty sockets; and, excepting round the teeth, calcification of the alveolus seems very poor. This-is well shown in the radiographs (Fig. 4 and 6).

The plan of his jaws is normal in outline, the four teeth defining the corners. The angle of the jaw is obtuse, the horizontal ramus merging gently into the ascending part (Fig. 5). 
The boy has the typical nutcracker face associated with edentulous mouths, and this, with the ill-defined angle of the jaw, the thin hair, and the elongated cranium, give him a prematurely aged appearance. There are no clefts in lip or palate.

The boy's mouth is always dry since the saliva is scanty, and so he finds it difficult to chew and swallow dry foods and sweets without the aid of water. He is consequently very fond of spiced and highly-flavoured foods.

HAIR.-The hair over the head is fine and dry and first appeared at the age of 18 months. He has no eyebrows (Fig. 1), and almost white eyelashes. No lanugo hair is visible over his body, and none has appeared yet in the pubic and axillary regions. A few hair follicles were found in a section of skin from the anterior aspect of the arm above the elbow.

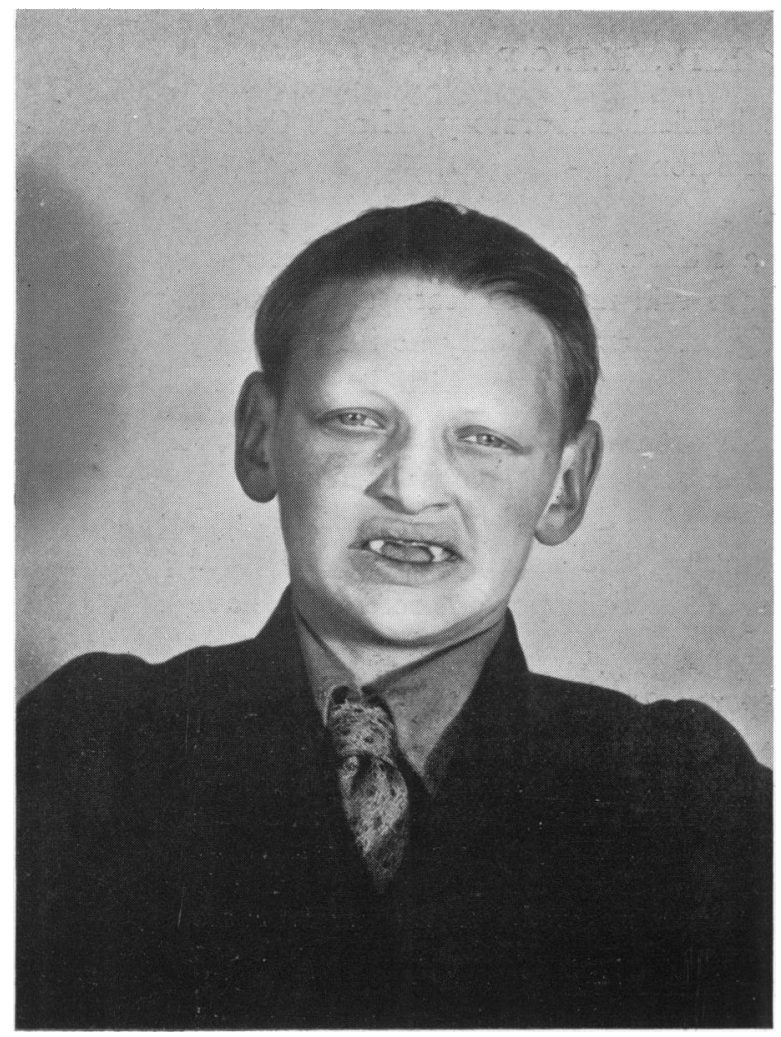

FIG. 1.

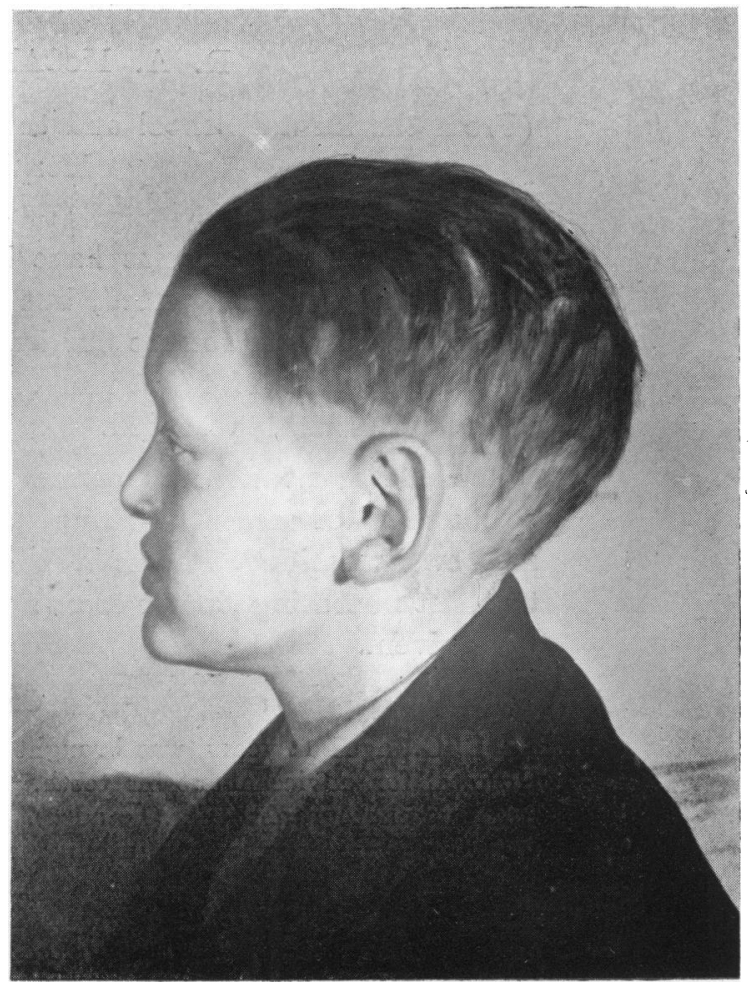

FIG, 2.

Eyes.-The boy cries normally and vision is six-sixths. No abnormality was was discovered in the lens, vitreous or retina. There is slight proptosis.

NOSE ANI) THROAT.-The boy has a hoarse voice which becomes worse after talking for some time. He has the saddle nose with depressed bridge which has been reported in other cases (Fig. 2), but his nose has been broken by injury which may partly account for its shape. Internally the nose is roomy, and there is atrophy of the nasal, nasopharyngeal, pharyngeal and laryngeal mucous membranes with some crusting. The sinuses are normal.

SkIN.-The skin is fine and dry and the boy has never sweated. There are no sebaceous papules on the face. The nipples are rudimentary and unpigmented and no gland tissue can be felt. A small portion of skin was taken for examination from the anterior aspect of the arm above the elbow and reported on as follows :- 'Sections 
FAMILIAL SEX-LINKED ECTODERMAL DYSPLASIA

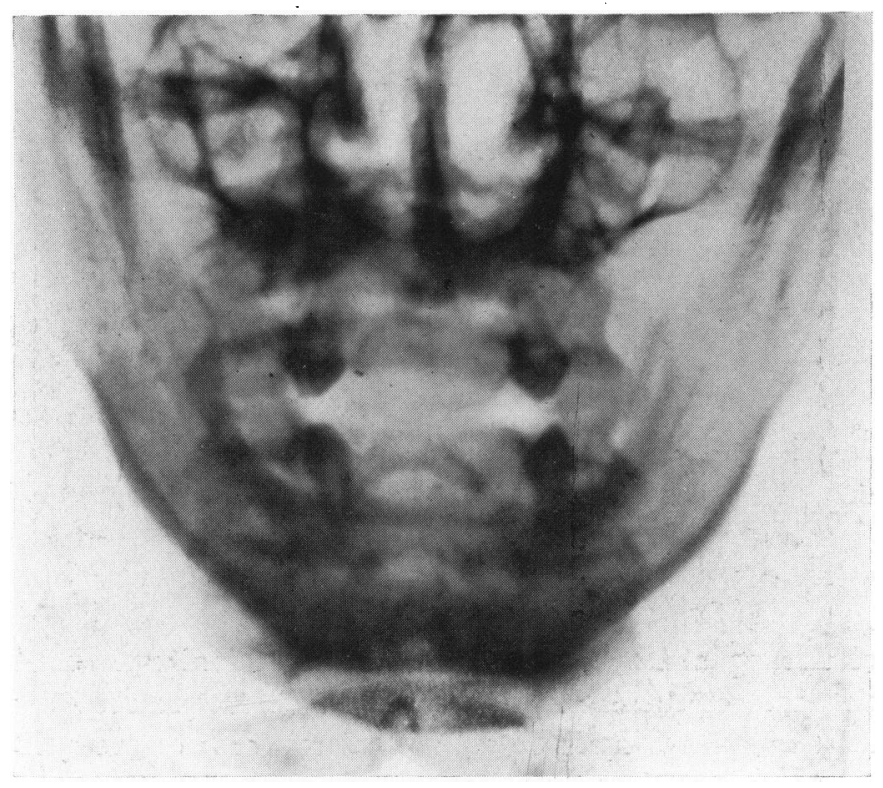

Fig. 3

Antero-posterior.

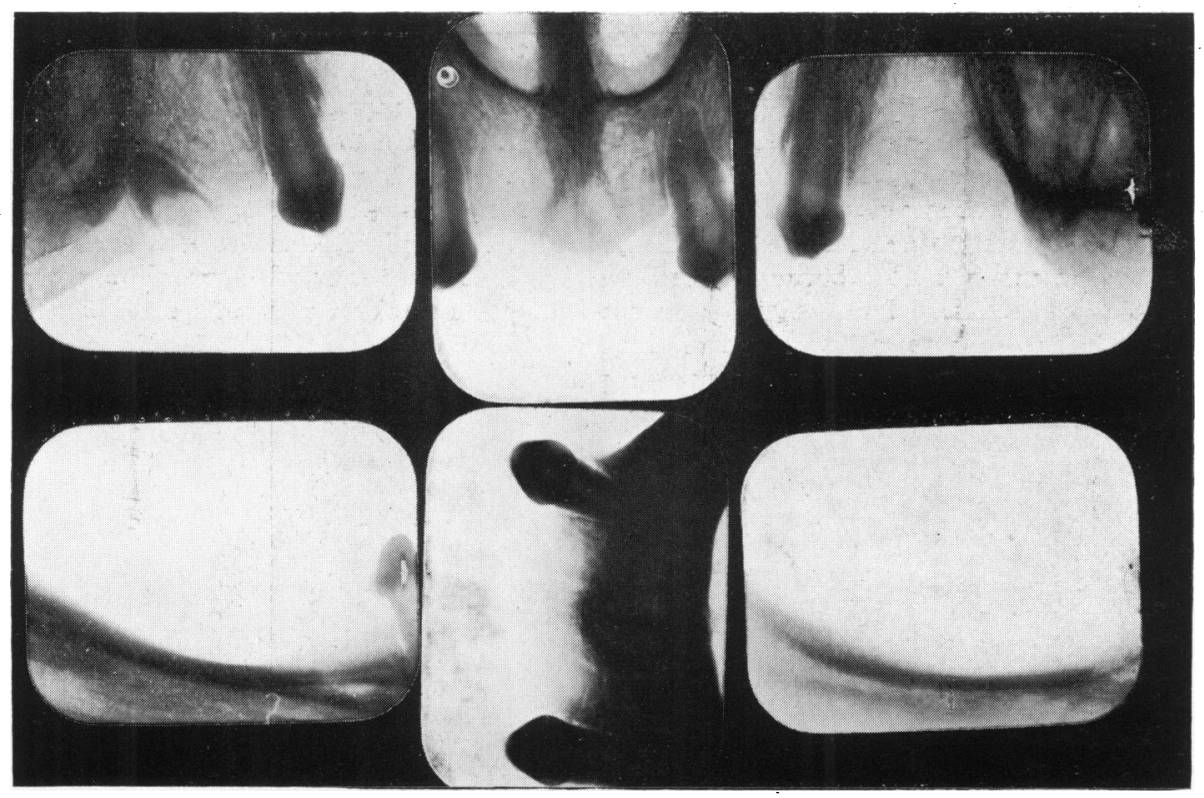

FIG: 4. 


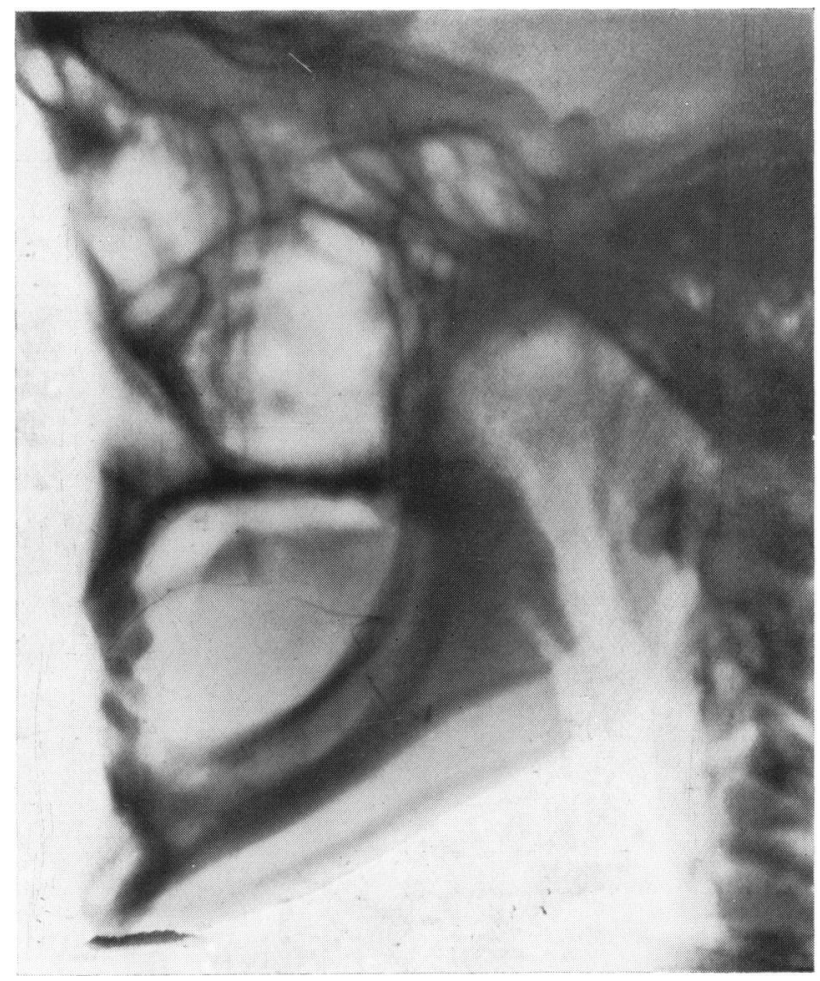

Fig. 5.

Lateral.

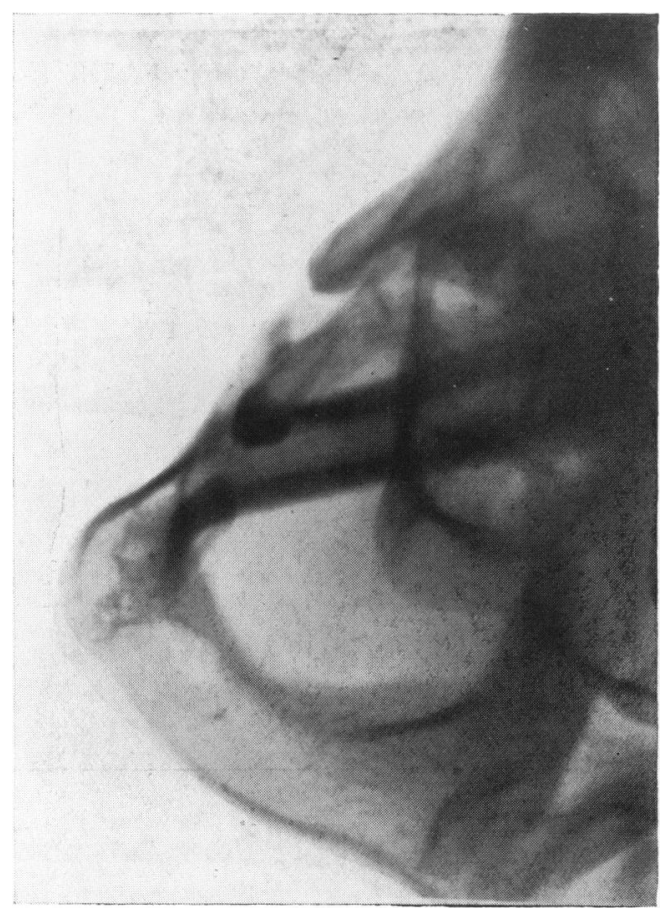

Fig. 6. 
of the skin show a very stratified epithelium with a few very small papillæ. There is a little keratin on the surface. No sweat, and only one sebaceous gland is seen, but a few hair follicles are present. In places there is a little lymphocytic infiltration.'

The nails are rather brittle, and have some longitudinal furrows, but are practically normal, and in another case would attract no attention.

Testes.-The testicles are normal in shape, size, and position.

Bones.-The supra-orbital ridges are pronounced and exaggerated (Fig. 2). Radiographically the long bones were reported as normal, but the sella turcica as small.

Biochemical investigations.-The Wassermann reaction is negative. Blood phosphorus : $4.4 \mathrm{mgm}$. per 100 c.c. Serum calcium: $9 \cdot 8 \mathrm{mgm}$. per 100 c.c. Serum phosphatase : 0.71 units. This last is definitely over the normal, but by itself may have no significance. Salivary juice produced by an acid drop contained abundant diastase.

The gastric residue was found to contain $0.265 \mathrm{gm}$. free $\mathrm{HCl}$ per cent., and 0.385 gm. of total acid as $\mathrm{HCl}$ per cent., which indicates a definite hyperchlorhydria.

Previous History. - As in all persons without sweat glands, the boy all his life has had the greatest difficulty in keeping cool. He has had the following illnesses :diptheria twice, scarlet fever twice, measles three times. He has also been the victim of numerous minor illnesses and has had a broken nose and leg.

Family History.-(see Fig. 7). The child has one sister who is normal. The father and all his family are stated to be normal. The mother's brothers and sisters are all normal. The maternal grandfather and one great uncle, who are both alive and have been seen and examined, have both had deficient sets of teeth. The

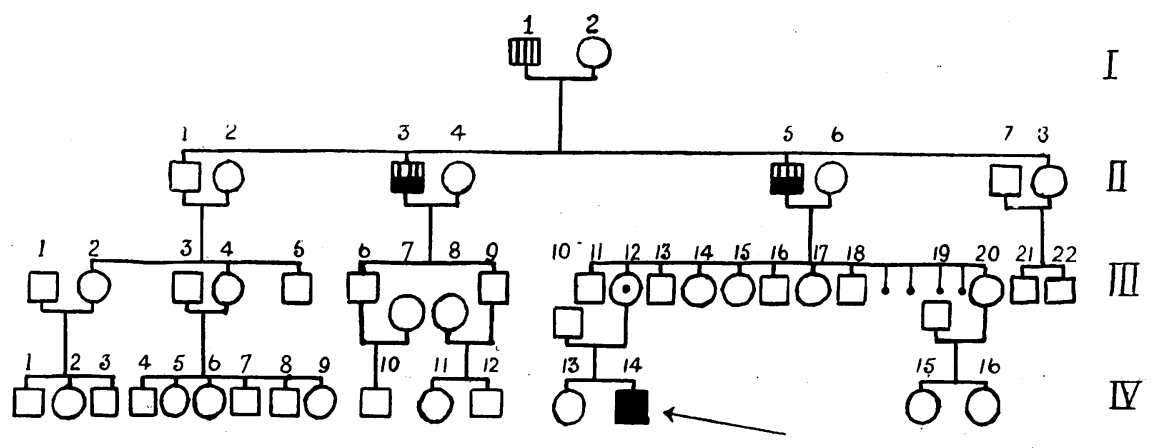

$\square=$ Normal male. O-Normal female. O.Carrier -Ectodermal defects. 血l-Allergic eczema. •-Miscarriage.

Fig. 7 .

IV. 14. The patient.

III. 10. The patient's father, one of a small family which cannot be traced.

III. 12. The patient's mother, who must have been a carrier.

II. 3 \& 5. Both men had a shortage of teeth, but sweated normally. Both, especially II, $\mathbf{3}$, have suffered from ' allergic eczema.'

II. 6. One of a family of eight (5 F. and $3 \mathrm{M}$.), the father and mother of whom were normal. No abnormality of skin or teeth can be found in this family or its descendants, of whom 54 can be traced.

I. 2. One of a family of six (3 F. and 3 M.). All are remembered as normal. Eight normal descendents can be traced.

I. 1. Said to have had a skin disease like II, 3 and 5 , all his life. Known to have had a good set of teeth when he died and to have sweated normally. One of a family of six (3 M. and $3 \mathrm{~F}$.). No abnormality can be traced in the seven known descendants. 
grandfather has only had 13 permanent teeth, most of which were preceded by deciduous teeth. The great uncle has had only 10 permanent teeth, preceded by 10 deciduous teeth, 6 in the upper and 4 in the lower jaw. It is impossible to be absolutely certain about the dentition of either of these men, as the teeth have mostly been lost by disease, but undoubtedly there was a deficiency. Both have also been troubled by an eczema which they inherited from their father, but in other ways they have been normal, and sweat profusely. No other allied abnormality can be traced in the family and as both grandparents are alive and most of the family live locally we have had favourable opportunities of investigating this.

There have been no consanguineous marriages.

\section{Discussion.}

Clinically this appears to be a typical case of ectodermal dysplasia of the major type as described by Cockayne and others.

Deficiency of teeth being so rare it is almost impossible not to associate the grandfather's and greatuncle's condition with that of the boy and this makes the case one of the sex-linked recessive type; but the unusual feature of this family history is the incompleteness of the defect in the older generation, and the complication of the allergic eczema.

Gibbs $^{4,5}$ reported that some members of his family group had denicient teeth, and implied that in them the defect was not fully developed, but the report is unfortunately not very detailed.

Although, therefore, the present case introduces a complication into the genetic aspect of the disease, it may ultimately help to throw light on its transmission by having drawn attention to an unusual, or possibly merely neglected, feature.

The authors acknowledge with thanks the help they have received from the photographic and other special departments of King's College Hospital. One of them (R. A. McC.) is indebted to the Medical Research Council for a part-time grant.

\section{REFERENCES.}

1. Christ, J., Arch. Dermat. and Syph., Chicago, 1913, CXVI, 685.

2. Cockayne, E. A., Inherited Abnormalities of the Skin and its Appendages, Lond., 1933.

3. Falconer, A. W., Lancet., Lond., 1929, ii, 656.

4. Gibbs, J. H., Dental Rec., London, 1915, XXXV, 669.

5. Gibbs, J. H., Dental Cosmos, Philad., 1916, LVIII, 352.

6. Harris, C. F., Proc. Roy. Soc. Med., Lond., 1928, XXI, 227.

7. Harwood, E. W., Trans. Odont. Soc., Lond., 1903-4, XXXVI, 203.

8. Janitzkaja, E., \& Rjabow, M., Ztschr. f. klin. Med., Berlin, 1928, CVII, 381.

9. McCracken, I. E., Brit. Med. J., Lond., 1931, ii, 225.

10. MacKee, G. M., \& Andrews, G. C., Arch. Dermat. and Syph., Chicago, 1924, X, 673.

11. Pitts, A. T., Proc. Roy. Soc. Med., Lond., 1923, XVI, 4.

12. Rushton, W., Trans. Odont. Soc., Lond., 1903-4, XXXVI, 199.

13. Smith, J., Arch. Dis. Child., Lond., 1929, IV, 215.

14. Tendlau, B., Arch. f. path. Anat., Berlin, 1902, CLXVII, 465.

15. Weber, F. P., Brit. J. Child. Dis., Lond., 1929, XXVI, 270.

16. Wechselmann, W., \& Loewy, A., Berl. klin. Wchnschr., Berlin, 1911, XLVIII, 1369.

17. Weech, A. A., Am. J. Dis. Child., Chicago, 1929, XXXVII, 766. 